\title{
Middle Ear Barotrauma in Military Aircrew: Analysis of Risk Factors
}

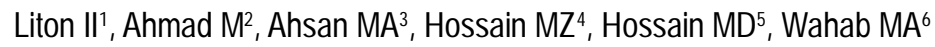

DOI: https://doi.org/10.3329/jafmc.v17i1.56714

\begin{abstract}
Introduction: Middle ear barotrauma is a common medical problem related to aviation; because the aviation environment exposes the aviator to a rapidly changing ambient pressure. Middle ear barotrauma occurs when the Eustachian tube failed to equalize middle ear pressure with ambient pressure during flight.
\end{abstract}

Objective: To determine the prevalence of middle ear barotrauma among aircrew on Bangladesh Air Force (BAF) and to find the risk factors of middle ear barotrauma.

Materials and Methods: This cross-sectional study was carried out on middle ear barotrauma in aircrew of BAF from February 2018 to January 2019. Aircrew who experienced fullness in the ear or ear pain during flight and visited the flight surgeon was enrolled in this study. Modified TEED scale used for grading of middle ear barotrauma.

Results: The study revealed middle ear barotrauma in the aircrew was $12.0 \%$ with a higher prevalence among the student pilots (14.2\%) compared with trained pilots (5.9\%), the mean age of aircrew was $23.2 \pm 3.6$ years. The right ear (43.5\%) was affected in most of the cases than the left ear $(34.8 \%)$. Most of the symptoms developed at a stage of descending (60.9\%). The duration (mean $\pm \mathrm{SD}$ ) of sickness was $7.6 \pm 3.7$ days.

Conclusion: Middle ear barotrauma or ear block is common in trainee aircrew but it is also seen in the experienced pilots who fly with upper respiratory tract infection (URTI) or a common cold. Appropriate training on ear physiology related to pressure changes inside the hypobaric altitude chamber can prevent the incidence of middle ear barotrauma.

Key-words: Barotrauma, Middle ear, Eustachian tube, Aircrew.

\section{Introduction}

The aviation environment exposes the aviator to rapidly changing ambient pressures, such pressure changes, which occur; more so in military flying affect the air containing cavities of the body which includes the semi-closed middle ear cavity. The aircrew should be able to equalize the pressure on each side of the tympanic membrane and this is only possible if the function of the Eustachian tube is normal. Failure to balance the pressure through the ear drum causes middle ear barotrauma ${ }^{1,2}$. The volume of air within the middle ear cleft varies considerably in response to pressure changes; it is $5 \mathrm{~cm}^{3}$ at sea level and will occupy nearly $7 \mathrm{~cm} 3$ at a cabin altitude of 8000 feet $^{3}$. The difficulty in clearing the ears during the flight is a common reason behind temporary or maybe permanent grounding of the aircrew ${ }^{4}$. Middle ear barotrauma is the most common medical complication related to aviation ${ }^{5}$. It can be defined as an acute or chronic traumatic inflammation in the middle ear cavity when the Eustachian tube unable to maintain the middle ear pressure at ambient pressure ${ }^{6}$.

The first description of the condition was given in 1783 by JCA Charles, a French physicist, who, becoming the first man to make a free ascent in a hydrogen balloon and complained of severe pain in his right ear during descent ${ }^{7}$. Barotrauma is the most prevalent medical problem associated with air travel and has been a causal factor in aviation accident ${ }^{8}$. The prevalence ${ }^{9}$ of middle ear barotrauma in trained aircrews is $2.4 \%$. The most common risk factor for middle ear barotrauma is Eustachian tube occlusion including coryza, upper respiratory tract infections (URTI), and allergy ${ }^{10}$. Common symptoms include fullness in the ear, earache, dizziness, ear discomfort, tinnitus or difficulty in hearing ${ }^{11}$. If it is very severe or long time remains untreated, other symptoms may occur such as otalgia and moderate to severe hearing loss ${ }^{12}$. Therefore, there is a need to identify potentially modifiable risk factors of disease onset and progression. The purpose of the study is to determine the prevalence of middle ear barotrauma and its risk factors in aviators.

\section{Materials and Methods}

This cross-sectional study was carried out on middle ear barotrauma in aircrew of Bangladesh Air Force (BAF) from February 2018 to January 2019. Aircrew who experienced fullness in the ear or ear pain during flight and visited the flight surgeon was enrolled and medical data of the aircrew were reviewed in this study. Medical registers, including the presence of ENT (ear, nose, and throat) diseases and history of nasal and ear surgery were also reviewed. Therefore, aircrew in this study was generally healthy and did not

1. Lt Col Iftekharul Islam Liton, MBBS, DAs Med, Classified Specialist in Aerospace Medicine, Air Headquarters, Bangladesh Air Force (E-mail: ifti8151@yahoo.com) 2. Col Mushtaq Ahmad, MBBS, DFM, MCPS, FRSPH, Professor \& Head, Department of Forensic Medicine \& Toxicology, AFMC, Dhaka 3. Col Mohammad Ahmed Ahsan, MBBS, DAs med, DAv med, Classified Specialist in Aerospace Medicine, Central Medical Board, Bangladesh Air Force 4. Lt Col Md Zakir Hossain, MBBS, FCPS, MCPS, DLO, Classified Specialist in ENT, Central Medical Board, Bangladesh Air Force 5. Lt Col Mohammad Delwar Hossain, MBBS, FCPS, MCPS, DLO, Classified Specialist in ENT, CMH Dhaka 6. Lt Col Md Abdul Wahab, MBBS, MD, Associate Professor of Biochemistry, AFMC, Dhaka. 
have any Eustachian tube dysfunction. If the aircrew experienced any discomfort during flight training, they were instructed to suspend the mission and reduce the flight altitude. Even then if their symptoms continued or worsened after landing aircrew were advised to visit flight surgeon or ENT specialist. Symptomatic treatment was given to each subject during illness. Nasal decongestant, Acetaminophen $500 \mathrm{mg}$, and antihistamines were given according to the symptoms of the aircrew. The TEED scale was developed in 1944. It was composed of 5 levels of grading, ear barotrauma and was not intended or developed for the evaluation of clinical patients ${ }^{13}$. Later on it has been modified by Edmonds et al which discern six degrees of barotrauma ${ }^{14}$. Modified TEED classification was used for degree or grading of middle ear barotrauma sustained by aircrew (Table-I). Preflight medical examination was done before flying, the aircrew was under follow-up and temporary flying restrictions were imposed on aircrew until they improved. The improvement of middle ear barotrauma was defined as the resolution of symptoms and normal transparency without any effusion or perforation of the tympanic membrane. Decompression test profiles were carried out at hypobaric altitude chamber in case-to-case basis. The duration of sickness was considered as the period from diagnosis to the improvement of middle ear barotrauma. Aircrew who were absent during follow-up were excluded from the study. Descriptive statistics were carried out for all variables. We used Chi-square to find associations between risk factors and ear barotrauma. Data were analyzed using SPSS version 21 and the level of significance was at $p<0.05$.

Table-I: Modified TEED Classification for middle ear barotrauma ${ }^{14}$

\begin{tabular}{|c|l|}
\hline Grade & \multicolumn{1}{|c|}{ Findings on Otoscopy } \\
\hline Grade 0 & Symptoms without otoscopic signs \\
\hline Grade 1 & $\begin{array}{l}\text { Diffuse redness and retraction of the tympanic } \\
\text { membrane }\end{array}$ \\
\hline Grade 2 & $\begin{array}{l}\text { Grade 1 changes plus slight hemorrhage within } \\
\text { the tympanic membrane }\end{array}$ \\
\hline Grade 3 & $\begin{array}{l}\text { Grade 1 changes plus gross hemorrhage within } \\
\text { the tympanic membrane }\end{array}$ \\
\hline Grade 4 & $\begin{array}{l}\text { Dark and slightly bulging tympanic membrane due } \\
\text { to free blood in the middle ear; a fluid level may } \\
\text { also be present }\end{array}$ \\
\hline Grade 5 & $\begin{array}{l}\text { Free hemorrhage into the middle ear with } \\
\text { tympanic membrane perforation; blood can be } \\
\text { seen outside or within the ear canal }\end{array}$ \\
\hline
\end{tabular}

\section{Results}

This study includes 192 pilots; the mean age of the pilots was 23.3 \pm 3.6 years (17 to 30 years) (Table-II). There was $23(12.0 \%)$ incident of middle ear barotrauma from 23 pilots (21 male, 2 female) among them 20 were student pilots (Table-III). Most common symptoms included fullness of ear 8 (34.8\%), ear pain/ear discomfort 7 (30.4\%), blocked nose 5 (21.7\%), tinnitus 2 (8.7\%) and hearing loss 1 (4.4\%) (Figure-1). There were 10 cases (43.5\%) affect the right ear and 8 cases (34.8\%) affected the left ear; 5 cases (21.7\%) were bilateral ear (Figure-2). Most symptoms were at a stage of descending 14 (60.9\%). Barotrauma was graded according to modified TEED classification 08 cases (34.8\%)\%) were classified as Grade 0, 10 cases (43.5\%) as Grade 1, 03 cases (13.0\%) were Grade 2 and 02 cases (8.7) as Grade 3. None were classified as Grade 4 and 5 [Fig-3]. The mean duration of sickness was $7.6 \pm 3.7$ days (range $5-90$ days). The duration of sickness was categorized into three groups: group 1 (who were improved within 5 days), group 2 (who were improved within 7 days) and group 3 (sickness duration was $>7$ days) (Table- IV). One case took 90 days to resolve completely. Aircrews with barotrauma had history of ear or nose infection (URTI) (p-value .001), history of nose lear operation ( $p$-value .011), allergic rhinitis ( $p$-value .021) (Table-V).

Table-II: Age and sex distribution of the aircrews ( $n=192)$

\begin{tabular}{|l|c|c|}
\hline \multirow{2}{*}{ Age group (years) } & \multicolumn{2}{|c|}{ Sex } \\
\cline { 2 - 3 } & Male (\%) & Female (\%) \\
\hline$<20$ & $66(34.4)$ & $09(4.7)$ \\
\hline $20-25$ & $64(33.3)$ & $04(2.1)$ \\
\hline $26-30$ & $49(25.5)$ & - \\
\hline \multicolumn{2}{|c|}{ Mean \pm SD $=23.3 \pm 3.6 ;$ Range $=17-30$} \\
\hline
\end{tabular}

Table-III: Prevalence of middle ear barotrauma among aircrews $(\mathrm{n}=192)$

\begin{tabular}{|l|c|c|c|}
\hline \multirow{2}{*}{$\begin{array}{l}\text { Type of } \\
\text { Aircrew }\end{array}$} & \multicolumn{2}{|c|}{ Number of Aircrew } & \multirow{2}{*}{ p-value } \\
\cline { 2 - 3 } & Total & Middle ear Barotrauma(\%) & \\
\hline Student pilot & 141 & $20(14.2 \%)$ & \multirow{2}{*}{$>05$} \\
\hline Trained Pilot & 51 & $03(5.9 \%)$ & \\
\hline Total (\%) & 192 & $23(12.0 \%)$ & \\
\hline
\end{tabular}

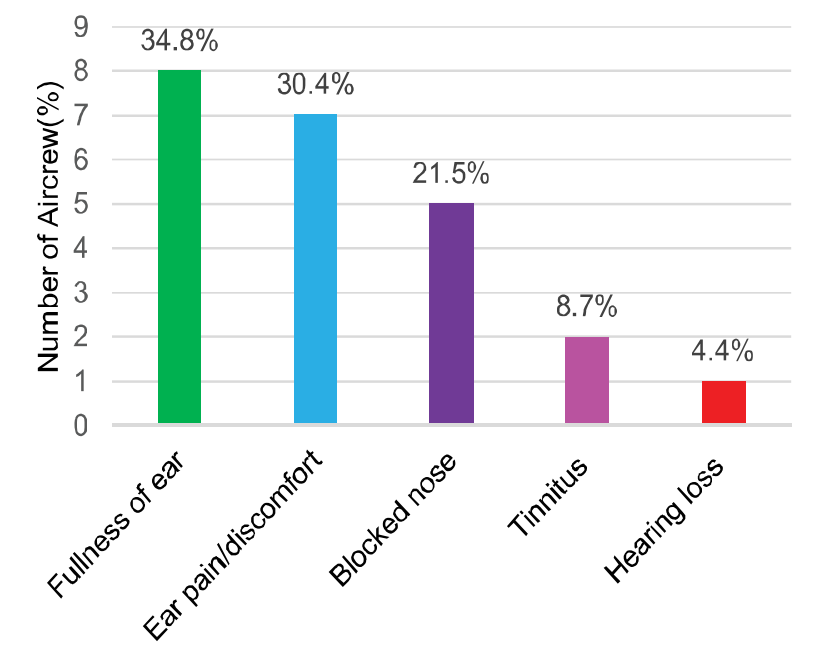

Figure-1: Symptoms associated with middle ear barotrauma of aircrews $(n=23)$ 


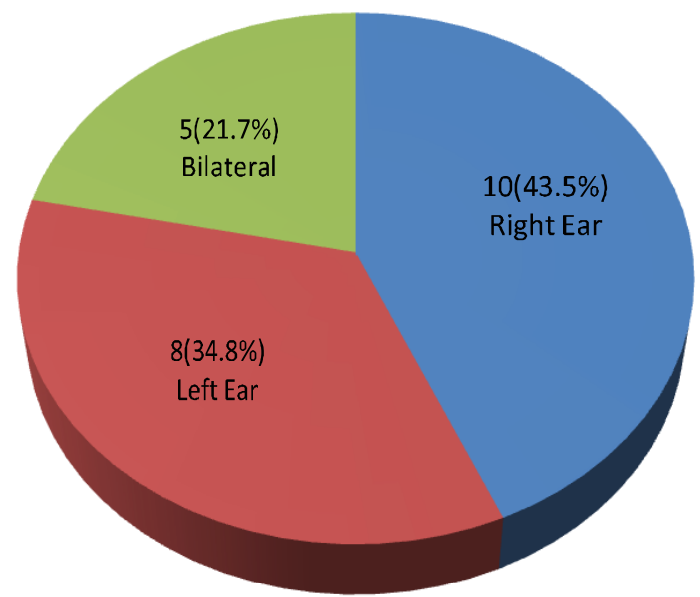

Figure-2: Barotrauma affected ear

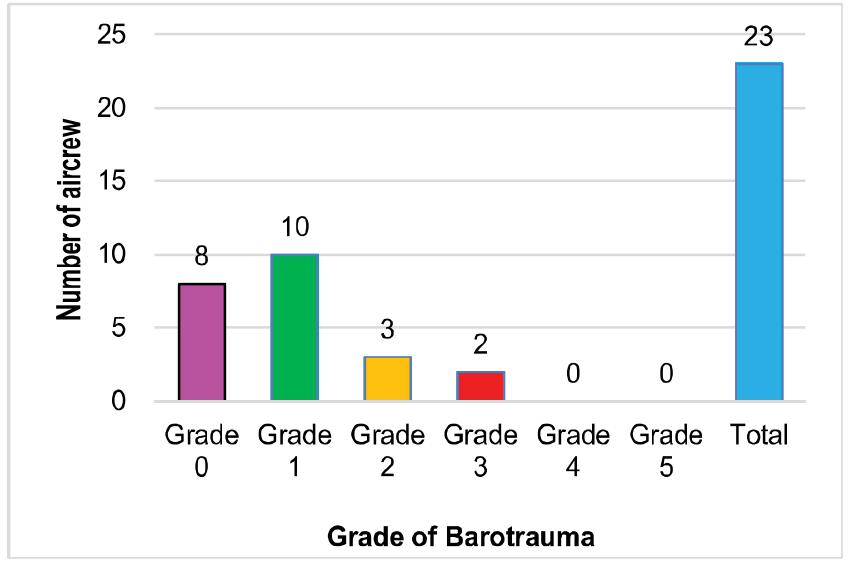

Figure-3: Grading of middle ear barotrauma according to modified TEED classification $(n=23)$

Table-IV: Duration of sickness of aircrew $(n=23)$

\begin{tabular}{|l|c|c|c|}
\hline \multicolumn{1}{|c|}{ Grade } & $\begin{array}{c}\text { Number of } \\
\text { Aircrews }(\%)\end{array}$ & $\begin{array}{c}\text { Mean } \pm \text { SD } \\
\text { Range }\end{array}$ & p-value \\
\cline { 1 - 2 } Grade $1(<5$ days $)$ & $16(69.6 \%)$ & \multirow{2}{*}{$7.6 \pm 3.7$} & \multirow{2}{*}{$<0.05$} \\
\cline { 1 - 2 } Grade 2(5-7 days) & $5(21.7 \%)$ & $(5-90$ days $)$ & \\
\cline { 1 - 2 } Grade 3 $>7$ days $)$ & $2(8.7 \%)$ & & \\
\cline { 1 - 2 } Total & $23(100 \%)$ & \\
\hline
\end{tabular}

Table-V: Risk factor for middle ear barotrauma in aircrew.

\begin{tabular}{|c|c|c|c|c|}
\hline \multirow[b]{2}{*}{ History of } & \multicolumn{3}{|c|}{ Middle ear barotrauma } & \multirow[b]{2}{*}{$\mathrm{p}$-value } \\
\hline & & $\begin{array}{c}\text { With }(n=23) \\
n(\%)\end{array}$ & $\begin{array}{c}\text { Without }(n=169) \\
n(\%)\end{array}$ & \\
\hline \multirow{2}{*}{ URTI } & Yes & 07(30.4\%) & $06(3.6 \%)$ & \multirow[b]{2}{*}{$<0.001$} \\
\hline & No & $16(69.6 \%)$ & $163(96.5 \%)$ & \\
\hline \multirow{2}{*}{$\begin{array}{l}\text { Nosel Ear } \\
\text { Operation }\end{array}$} & Yes & $06(26.1 \%)$ & $08(4.7 \%)$ & \multirow[b]{2}{*}{$<0.05$} \\
\hline & No & $17(73.9 \%)$ & 161(95.3\%) & \\
\hline \multirow{2}{*}{$\begin{array}{l}\text { Allergic } \\
\text { rhinitis }\end{array}$} & Yes & $05(21.74 \%)$ & $13(7.7 \%)$ & \multirow[b]{2}{*}{$<0.05$} \\
\hline & No & $18(78.26 \%)$ & $156(92.3 \%)$ & \\
\hline
\end{tabular}

\section{Discussion}

Barotrauma is defined as an injury produced by mechanical forces caused by the change of pressure on a gas-filled space. Middle ear barotrauma is the term that describes any damage to the ear resulting from such changes in pressure ${ }^{15}$. Physiologically anything that may impede the ability of the Eustachian tube to normalize the pressure changes will predispose to middle ear barotrauma. The most common predisposing factor for middle ear barotrauma is the upper respiratory tract infection (URTI) which causes the Eustachian tube edema. Other factors that might cause a similar problem are allergy and rhinitis ${ }^{16}$. The development of middle ear barotrauma is dependent upon the rate of descent or the rate of ambient pressure increase in the middle ear cavity. The latter is affected by the patency of the lumen and by the degree, frequency, and duration of Eustachian tube opening ${ }^{17}$. Visual inspection of the tympanic membrane reveals the degree of middle ear barotrauma.

Different studies have shown that $20-50 \%$ of passengers reported earache during the flight or after landing ${ }^{18}$. In this study, $12.0 \%$ aircrew developed middle ear barotrauma among them $87.0 \%$ were student pilot. The most common middle ear barotrauma symptoms were the fullness of ear and earache $65.2 \%$ during the stage of descending. A study done by Stangerup SE et al found the prevalence of middle ear barotraumain aircrew is 2 to $17 \%$ which is similar to our study ${ }^{19}$. A study done by Khayat ISSK et al in Saudi Airlines Medical Services found 39\% barotrauma with $14.4 \%$ repeated attacks in aircrew. Main symptoms were ear pain and discomfort (68.3\%) at the stage of flight take off ${ }^{20}$. A study done by Brown TP et al which is similar to the current study of common symptoms of barotrauma ${ }^{11}$. The duration of sickness due to middle ear barotrauma is considered the most important concern for the trainee pilots. Due to barotrauma if flight training interrupted for longer duration student pilots might drop out of flight-training programs. The mean disease duration was 7.6 day and 16 cases (69.6\%) improved in $<5$ days, while 5 cases (21.7\%) resolved between 5-7 days without any sequelae. One of the aircrew were put into the hypobaric altitude chamber at a height of 10,000 feet ascending and descending rate was 500 feet, 1000 feet and 2000 feet/minute to check the Eustachian tube patency; before giving the flight fitness. In this study there was a significant correlation of between grading of barotrauma and duration of sickness. In risk factors analysis the result showed association between middle ear barotrauma and risk factors like-flying with URTI, ear or nose operation and allergy; which is similar to the study done by King PF et a ${ }^{10}$.

\section{Conclusion}

Middle ear barotrauma occur mostly during the descending phase of the flight and result from failure to open the closed Eustachian tube actively. Middle ear barotrauma or ear block is particularly common in trainee aircrew but is also seen in experienced aviators who fly with upper respiratory tract infection (URTI) or a common 
cold. Therefore aircrew should be made aware of the danger of flying with an upper respiratory tract infection or a common cold. Appropriate training on ear physiology related to pressure change on the ground in the hypobaric altitude chamber might prevent the incidence of trainee pilot's middle ear barotrauma.

\section{References}

1. Farmer JC Jr. Eustachian Tube Function and Otologic Barotrauma. Ann Otol Rhinol Laryngol. 1985 (Suppl 2); 94(5):45-7.

2. Ashton $\mathrm{DH}$, Watson $\mathrm{LA}$. The use of tympanometry in predicting otitic barotrauma. Aviat Space Environ Med. 1990; 61(1):56-61.

3. Moser M. Fitness of civil aviation passengers to fly after ear surgery. Aviat Space Environ Med. 1990; 61:735-7.

4. Ghosh S and Kumar NA. Study of middle ear pressure in relation to Eustachian tube patency. Indian Journal of Aerospace Medicine. 2002; 46(2):27-30.

5. Duplessis C, Fothergill D, Gertner J et al. A Pilot Study Evaluating Surfactant on Eustachian Tube Function in Divers. Mil Med. 2008; 173(12):1225-32.

6. Mirza S, Richardson $\mathrm{H}$. Otic barotrauma from air travel. J Laryngol Otol. 2005; 119(05).

7. Health HD, Williams DR. Man at High Altitude. Edinburgh: Churchill Livingstone, 1981.

8. Lews ST. Barotrauma in United States Air Force accident/incidents. Aerospace Med. 1974; 44:1059-61.

9. Morgagni $F$, Autore A, Landolfi $A$ et al. Predictors of ear barotrauma in aircrews exposed to simulated high altitude. Aviat Space Environ Med. 2012; 83(6):594-597.

10. King PF. The Eustachian tube and its significance in flight. J
Laryngol Otol. 1979; 93(07):659-78.

11. Brown TP. Middle ear symptoms while flying. Postgrad Med. 1994; 96(2):135-42.

12. Aljurf TM, Olaish AH, BaHammam AS. Assessment of sleepiness, fatigue, and depression among Gulf Cooperation Council commercial airline pilots. Sleep Breath. 2017; 22(2):411-9. 13. ONeill OJ, Frank AJ. Ear Barotrauma. [Updated 2019 Jun 17]. In: Stat Pearls [Internet]. Treasure Island (FL): Stat Pearls Publishing; 2019.

14. Edmonds C. Ear barotrauma. In: Edmonds C, Lowry C, Pennefather J, Walker R. Diving and subaquatic medicine. 4th ed. London: Arnold, 2002:73-91.

15. Bove AA. A Short History of Diving and Diving Medicine. In: Bove AA (ed). Bove and Davis' Diving Medicine. Philadelphia: WB Saunders, 1997:3-6.

16. David P Gradwell and Air Commodore Rainford DJ. Ernsting's Aviation and Space Medicine, 5th ed, 2016:527- 8.

17. Dickson EDD, King PF. The Incidence of Barotraumas in Present Day Service Flying. Flying Personnel Research Committee Report No 881. London: Air Ministry, 1954.

18. Buchanan BJ, Hoagland J, Fischer PR. Pseudoephedrine and air travelassociated ear pain in children. Arch Pediatr Adolesc Med. 1999; 153(5):466-8.

19. Stangerup SE, Klokker M, Vesterhauge $S$ et al. Point Prevalence of Barotitis and Its Prevention and Treatment with Nasal Balloon Inflation: A Prospective, Controlled Study. Otol Neurotol. 2004; 25(2):89-94.

20. Khayat ISSK, Garout IR, Alahmadi LS et al. The Prevalence and Risk Factors of OticBarotrauma among Aircrew Members. Int J Life Sci Pharma Res. 2019; 9(2):24-30. 